\title{
Relationships with intimate partner, best friend, and parents in adolescence and early adulthood: A study of the saliency of the intimate partnership
}

\author{
Wim H.J. Meeus, Susan J.T. Branje, Inge van der Valk and Muriel de Wied \\ Research Center Adolescent Development, Utrecht University, The Netherlands
}

\begin{abstract}
We studied the psychological importance of best friend and intimate partner in the personal network of adolescents and early adults, and links between relationships and emotional problems as well as links between relationships themselves. A series of hypotheses derived from the "intimate partner (IP) general saliency perspective" and "the intimate partner (IP) early adult saliency perspective" was tested. The IP general saliency perspective predicts that the relationship with intimate partner is psychologically more meaningful than the relationship with best friend in adolescence and early adulthood. The IP early adult saliency perspective predicts that the relationship with intimate partner does not have superior psychological value in adolescence and acquires it in early adulthood. Data of Waves 1 and 3 of a six-year longitudinal study of 1041 adolescents and early adults, aged 12-23 at Wave 1 , were used. Results showed that when early adults and adolescents make the shift from best friend to intimate partner, relational commitment becomes stronger and emotional problems become smaller, supporting the IP general saliency perspective. Results also showed that only in early adulthood was a stronger commitment to intimate partner related to less emotional problems, and more parental support was linked to stronger relational commitment to intimate partner. These findings clearly support the IP early adult saliency perspective. In sum, when adolescents and early adults make the transition to the intimate partnership they enter a psychologically more meaningful relationship. When individuals enter early adulthood the psychological value of the intimate partner relationship becomes more salient: the quality of the intimate relationship becomes more stable and linked to emotional adjustment.
\end{abstract}

Keywords: adolescence; best friend; early adulthood; emotional problems; intimate partner; parents; saliency of intimate partner

The development of intimacy and commitment to intimate partner is one of the important tasks of adolescents and early adults (Erikson, 1968). In this article, we will study the following issues: (a) the psychological saliency of intimate partner and best friend in terms of relational commitment and emotional adjustment, (b) whether the link between quality of relationship and emotional adjustment is different for relationships with intimate partner and best friend, and (c) how quality of the relationship with an intimate partner is linked to quality of the relationship with parents and best friend. To examine these issues, we will use longitudinal data.

\section{Two perspectives on the psychological saliency of intimate partner and best friend}

Intimate relationships are generally considered to be more encompassing than best friend relationships. Hazan and Shaver (1987) have argued that the adult intimate partner relation is a manifestation of the attachment system. Intimate partners offer proximity, safety, security, and care to each other in the same manner as parents to their children. These attachment related functions grow from early adolescence on (Furman \&
Wehner, 1994; Sullivan, 1953). Relationships with best friends are generally not considered to take on attachment quality.

From the literature two perspectives on adolescent and early adult relationships with intimate partner and best friend arise. The first perspective entails that the intimate partnership is a developmentally more mature and psychologically more salient relationship than the best friend relationship in adolescence and in early adulthood. We label this view "the intimate partner (IP) general saliency perspective" (from now on general saliency perspective). The second perspective entails that the intimate partner relationship only becomes more salient than the best friend relationship in early adulthood. In early adolescence, intimate partners fullfill the same functions as best friends and offer companionship and reciprocity (Nieder \& Seiffge-Krenke, 2001; Seiffge-Krenke, 2003), whereas in late adolescence and early adulthood intimate partnerships develop into loving and caring bonds and take on attachment quality (Katz \& Beach, 1997). We label this view the "intimate partner (IP) early adult saliency perspective" (from now on early adult saliency perspective).

When we link both perspectives to the theory of the development of romantic relationships recently proposed by Brown (1999), the general saliency perspective suggests that the
This research was supported by grants from the Dutch Organization for Scientific Research (NWO) to the Utrecht Study on Adolescent Development (USAD) 1991-1997. Correspondence concerning this article should be addressed to Wim Meeus, Research Center Adolescent Development, Post Box 80.140, 3508 TC Utrecht, The Netherlands; e-mail: W.Meeus@fss.uu.nl 
relationship with intimate partner is psychologically more salient than the relationship with best friend in all four phases: the initiation phase (early adolescence), the status phase (middle adolescence), the affection phase (late adolescence), as well as the bonding phase (early adulthood). The early adult saliency perspective suggests that only in the bonding phase does the greater saliency of the intimate partner appear.

A number of empirical studies offer support for both perspectives. Our review of these studies will discuss four topics.

Saliency of intimate partner and best friend. A number of crosssectional studies has documented that from adolescence onwards the relationship with intimate partners is more salient than the relationship with best friends. In four adolescent samples, higher levels of support, reliable alliance, and intimacy have been established for intimate partnership than for the best friend relationship (Connolly, Furman, \& Konarski, 2000; Connolly \& Johnson, 1996; Seiffge-Krenke, 2000, 2003). These findings support the general saliency perspective, and suggest that already in adolescence the relationship with intimate partner is psychologically more mature than the relationship with best friend.

Having a best friend and/or intimate partner and emotional adjustment. Numerous studies have shown that having a best friend fosters emotional adjustment in adolescence and early adulthood (see, for example, the following recent studies: Daley \& Hammen, 2002; La Greca \& Harrison, 2005), or at least does not lead to emotional maladjustment (Brendgen, Vitaro, Doyle, Markiewicz, \& Bukowski, 2002). A different picture emerges when we look at intimate partnership in adolescence and early adulthood. Existing research suggests an age specific pattern. A number of studies have shown that early adolescent involvement in intimate relationships goes together with various forms of emotional maladjustment such as low selfesteem, delinquency, depression, and low emotional health (Brendgen et al., 2002; Joyner \& Udry, 2000; Meeus, Branje, \& Overbeek, 2004; Neeman, Hubbard, \& Masten, 1995; Zimmer-Gembeck, Siebenbruner, \& Collins, 2001). On the other hand, numerous studies revealed that early adults with intimate partners are happier than adults without intimate partners (Katz \& Beach, 1997; Kurdek, 1991; Lee, Seccombe, \& Shehan, 1991; Marks \& Lambert, 1998). These findings seem to support the early adult saliency perspective: having an intimate partner fosters emotional adjustment in young adulthood but not in adolescence.

Quality of relationship with best friend and intimate partner and emotional adjustment. A limited number of studies have looked at the link between quality of relationship with best friend and intimate partner and emotional adjustment simultaneously. Two sets of findings are of particular interest here. In the first place the link between quality of relationship with intimate partner and emotional adjustment seems to vary with age: Zimmer-Gembeck et al. (2001) found no association with internalizing problems in early adolescence; La Greca and Harrison (2005) and Daley and Hammen (2002) found a significant link with social anxiety and depression in late adolescence; while Segrin, Powell, Givertz, \& Brackin (2003) found a significant association with depression in early adulthood. These findings are more supportive of the early adult saliency perspective than of the general saliency perspective.
In the second place, La Greca and Harrison (2005) found that the links between quality of relationship with best friend and intimate partner and emotional adjustment has the same effect size in late adolescence, while Daley and Hammen (2002) found the effect size of the link with the relation with intimate partner to be bigger than with the best friend relationship. These findings are not supportive of the general or early adult saliency perspective.

Parents and intimate partner. Attachment theory (Bowlby, 1969) predicts a positive linkage between the parentadolescent relationship and intimate partner relationship. In the early parent-child interaction the child develops a working model of personal relationships and the self in personal relationships that generalizes to later relationships. A number of cross-sectional and longitudinal studies with early adults provide support for a positive linkage between parent-child and intimate partner relationships, with small to medium effect sizes (<.30). In cross-sectional studies, positive associations have been found between attachment style and quality of the intimate partner relationship (Collins \& Read, 1990; SeiffgeKrenke, 2006; Simpson, 1990). Longitudinal studies further revealed positive associations over time between nurturinginvolved parenting and affection in the intimate partner relationship (Conger, Cui, Bryant, \& Elder, 2000), flexible control by mother and happiness in the intimate partner relationship (Feldman, Gower, \& Fischer, 1998), reliable alliance in the parent-child relationship and the intimate partner relationship (Seiffge-Krenke, Shulman, \& Klessinger, 2001), and parental acceptance and intimacy and encouragement of independence in the intimate partner relationship (Scharf \& Mayseless, 2001).

However, studies conducted with adolescents show a different pattern. Only one study conducted by Connolly \& Johnson (1996) found a positive association between parental support and support by intimate partner. At least four studies reported no linkages between the parent-adolescent and intimate partner relationship: Furman, Simon, Shaffer, and Bouchey (2002) didn't find a significant association between working models of, and relational styles in, the parentadolescent and intimate partner relationship; Miller and Hoicowitz (2004) didn't show a significant association for most of their measures of anxiety and avoidance in the parentadolescent relationship and the intimate partner relationship; Seiffge-Krenke et al. (2001) failed to report a significant longitudinal link between reliable alliance in the parent-adolescent relationship and the intimate partner relationship; and finally Shulman and Scharf (2000) didn't find an association between affection in both relationships. These findings suggest an agespecific pattern and support the early adult saliency perspective. In adolescence there is no significant link between the parent-adolescent relationship and intimate partner relationship, whereas in early adulthood this link emerges. Furman et al. (2002) suggest that this could be due to the fact that in adolescence intimate partner relationships are neither longlasting nor developmentally mature; serious investments and commitments are lacking in the adolescent intimate partner relationship and therefore a resemblance with the long-lasting and intense parent-adolescent relationship is improbable. Apart from testing the general and early adult saliency perspective, we will also study the linkage between the relationship with best friend and intimate partner. Several theoretical considerations make it plausible to assume a linkage between 
quality of the relationship with best friends and quality of the relationship with intimate partners. First of all, both relationships are similar in various respects: they are voluntarily chosen, egalitarian, and based on reciprocity (Furman, 1999; Furman \& Wehner, 1994; Scharf \& Mayseless, 2001). Second, the best friend relationship (i.e., the first egalitarian relationship in a persons' life) may constitute a playground of learning the principles of egalitarian and reciprocal relationships that may generalize to later relationships with peers and intimate partners (Connolly \& Johnson, 1996; Furman \& Wehner, 1994; Sullivan, 1953). Empirical studies, both concurrently as well as longitudinally, support the idea of linkages between the best friend and intimate partner relationship. Connolly and Johnson (1996), for example, established a positive association between support from best friend and support from intimate partner. Also, Furman et al. (2002) demonstrated positive associations between working models of best friend and intimate partner relationships, as well as positive associations between relational styles in best friend and intimate partner relationships. Again, Miller and Hoicowitz (2004) showed that anxiety and avoidance in the best friendship and intimate partner relationship are associated. Connolly et al. (2000) reported longitudinal associations between support and negative interactions in the best friendship and intimate partner relationship, and Seiffge-Krenke (2000) found the same for intimacy.

\section{Research question and hypotheses}

Our overview reveals mixed evidence for both perspectives. Evidence for the general saliency perspective has been found in empirical studies that show that already in adolescence the intimate partner relationship is more supportive, affectionate, and intimate than the best friend relationship. Support for the early adult saliency perspective can be derived from empirical studies which show that in early adulthood the transition to intimate partnership fosters emotional adjustment, whereas this is not the case in adolescence, as well as from empirical studies which demonstrate that only in early adulthood a linkage between the quality of the parent-adolescent relationship and the intimate partner relationship exists. Overall, empirical support was stronger for the early adult saliency perspective than for the general saliency perspective. To test both perspectives, we will use data from Waves 1 and 3 of a six-year longitudinal study to study six hypotheses. In our analyses, we will concentrate on a central aspect of relationships with best friends and intimate partners, namely relational commitment (Duemmler \& Kobak, 2001; Rusbult, 1983; Scharf \& Mayseless, 2001). Relational commitment is defined as "the intent to persist in a relationship, including long-term orientation to the involvement as well as feelings of psychological attachment" (Rusbult, Martz, \& Agnew, 1998, p. 359).

Hypothesis 1, derived from the general saliency perspective, states that relational commitment to intimate partner will be stronger than to the best friend in adolescence and in early adulthood. Hypothesis 2, derived from the early adult saliency perspective, states that emotional problems of early adults who have or get an intimate partner will diminish over time, whereas for adolescents this doesn't necessarily have to be the case. Hypothesis 3 has been formulated as an early adult saliency hypothesis and states that in early adulthood the negative link between relational commitment to intimate partner and emotional problems will be stronger than that between relational commitment to intimate partner and emotional adjustment in adolescence, and between relational commitment to best friend and emotional adjustment in early adulthood and adolescence. We formulated this hypothesis as an early adult saliency hypothesis, since support for the general saliency perspective was completely missing with regard to this issue. Hypothesis 4, derived from the early adult saliency perspective, states that the link between parental support and relational commitment to intimate partner will be stronger in early adulthood than in adolescence. Additionally we will test whether this link is also stronger than the link between commitment to best friend and emotional adjustment in early adulthood and adolescence. One additional early adult saliency hypothesis on the stability of relational commitment will be tested. Hypothesis 5 is based on the finding by Seiffge-Krenke (2003) that stability of the relationship with intimate partner increases with age and states that the six-year stability of relational commitment to intimate partner will be stronger than that of relational commitment to intimate partner in adolescence and that of relational commitment to best friend in early adulthood and adolescence. Finally, we will test a relationship linkages hypothesis not derived from the general saliency or early adult saliency perspective. Hypothesis 6 assumes that relational commitment to the best friend will be predictive of relational commitment to the intimate partner six years later.

Hypotheses 1, 2, 5 and 6 will be tested longitudinally. Hypotheses 3 and 4 will be explicitly tested for T 1 associations. Inspection of stability paths, cross-lagged paths and T3 associations will reveal whether these hypotheses hold over time.

\section{Method}

\section{Subjects}

Data for this study was collected as part of a broader multipurpose project, the Utrecht Study of Adolescent Development (USAD) 1991-1997 (Meeus \& 't Hart, 1993). In 1991, a national sample of 3392 Dutch adolescents aged 12 to 23 was drawn from an existing panel of 10,000 households. 'T Hart (1992) checked the representativeness of the first wave sample by comparing it with population figures published by the Dutch Central Statistical Office (CBS). No differences were found between the sample and the CBS figures with respect to district, urbanization level, educational level, and religious affiliation. The sample can therefore be regarded as representative of the Dutch indigenous adolescent population of the early 1990s. A random selection of 1300 subjects was targeted to be the sample for the longitudinal part of the study. Although all the 3392 subjects of the first wave gave their informed consent to remain participants in the longitudinal study, 822 of them ultimately refused to take part in the second or third wave. So, the non-response rate between Wave 1 and 3 was $24 \%$, and 1302 subjects were selected from the 2570 subjects eligible for the longitudinal study. The time-interval between the waves was three years. In this study we will use data of Waves 1 and 3, and cover a span of six years.

Analyses were carried out to test whether there were differences between the subjects that participated in the longitudinal sample and those who did not in terms of gender, age, educational level, and measures of parental support, relational commitment, and emotional problems. Since $n$ was greater 
than 3000 in most of these analyses, significance level was set at $p<.01$. Logistic analyses showed that remaining in the longitudinal sample was associated with gender $(B=-.26$, $p<.01)$ and age $(B=-.07, p<.01)$ and not with educational level (no contrast reaching $p<.01$ ). Fewer males and young adults stayed in the study than females and adolescents. Analyses of variance showed no differences between participants in the longitudinal study and non-participants in terms of parental support at Wave $1: F(1,3003)=4.48, p>.01$, relational commitment at Wave $1: F(1,3391)=.59, p>.05$, and emotional problems at wave $1: F(1,3134)=1.45, p>.05$. Additionally, we checked whether the associations between parental support, relational commitment, and emotional problems were different for those who stayed in the study and those who dropped out. The correlations between parental support and relational commitment were -.08 and -.06 respectively for participants and non-participants, correlations between parental support and emotional problems were -.27 and -.20 for participants and non-participants, while those between relational commitment and emotional problems were -.01 and -.07 respectively. In all cases the correlations of participants and non-participants did not differ significantly ( $p s>.05)$. Although the results of this study must be interpreted with caution, the findings concerning parental support, relational commitment, and emotional problems can be generalized to broader populations.

The sample consisted of 550 males (42\%) and 752 females $(58 \%)$. The respondents were evenly distributed over the four age categories (based on age at first wave): 321 early adolescents aged 12 to $14(25 \%), 341$ middle adolescents aged 15 to $17(26 \%), 261$ late adolescents aged 18 to $20(20 \%)$, and 379 young adults aged 21 to 23 (29\%). Further, the educational level of the respondents could be differentiated as $54 \%$ low-middle and $46 \%$ high. About $48 \%$ of all respondents had a religious affiliation, and $52 \%$ had none. In total, $99 \%$ of the sample consisted of adolescents who were of Dutch origin, and only $1 \%$ came from a different ethnic background.

\section{Procedure}

The respondents were interviewed in their homes. They were also asked to complete an extensive questionnaire in the presence of the interviewer. They were then given another questionnaire to fill out on their own within a week and send back to the research organization. All 1302 participants returned this second questionnaire in the three waves.

\section{Measures}

Parental support was assessed by six short questionnaire items. Respondents were asked to indicate on a 10-point scale (range 10-100) to what degree they receive social support in the domains of personal relationships, leisure time, and school/work from their father and mother. Cronbach's alphas for parental support were $.87, .88$, and .87 at Wave 1 , Wave 2, and Wave 3 respectively. Concurrent validity of the parental support measure has been demonstrated by correlations ranging from .45 to .56 between the scale of parental support and the parental attachment scale of the Inventory of Parent and Peer Attachment by Armsden and Greenberg (1987) (Helsen, Vollebergh, \& Meeus, 1999).

Relational commitment to best friend and intimate partner was assessed with the relational commitment scale of the Utrecht-
Groningen Identity Development Scale (U-GIDS, Meeus, 1996). The 6-item scale includes items tapping commitment to stay in the relationship and involvement in the relationship. Examples of the items are: "My best friend/intimate partner allows me to face the future with optimism" (intent to persist in the relationship), and "I'm sure my best friend/intimate partner was the best choice for me" (psychological attachment to the relationship). A five-point Likert type scale was used with response categories ranging from $1=$ completely untrue to $5=$ completely true. Cronbach's alphas of the scale for relational commitment were $.88, .89$, and .89 at Wave 1 , Wave 2 , and Wave 3 respectively. Earlier analyses showed a strong convergent-divergent validity of the scale of relational commitment (Meeus, 1996). Concurrent validity of the relational commitment scale has been demonstrated in two samples: a sample of 500 Dutch adolescents aged 12-18 (Rispens, Hermanns, \& Meeus, 1996), and a sample of 3300 Dutch adolescents aged 12-24 (Meeus \& 't Hart, 1993). In these samples significant associations (correlations of .45 and .19, respectively) were found between relational commitment and Harter's social competence scale (Harter, 1985), and between relational commitment and Block's measure of ego-resiliency (Block \& Kremen, 1996).

Emotional problems were assessed by a questionnaire measure of psychological stress and depression (shortened version of the General Health Questionnaire, GHQ: Goldberg, 1978; Kienhorst, de Wilde, van den Bout, \& Diekstra, 1990; Meeus, 1994), and two additional items related to well-being (Cantril ladder, Cantril, 1965) and suicide (Diekstra, Garnefski, de Heus, de Zwart, van Praag, \& Warnaar, 1991). The GHQ comprises two subscales: psychological stress (six items), and depression (four items). Adolescents were asked to indicate on a 4-point scale to what extent they experienced various symptoms of stress and depression (e.g., feeling tense and nervous, feeling unhappy and dejected) during the past four weeks $(1=$ much more than usual to $4=$ not at all $)$. Internal consistencies of both scales were high (alphas across waves ranged from .88 to .90 for psychological stress and .80 to .84 for depression); so mean scores were derived for each subscale. Additionally, adolescents were asked to indicate on a 10-point scale how they generally felt $(1=$ very bad to $10=$ very well $)$, and asked to indicate on a 4-point scale whether they had considered committing suicide during the last 12 months $(1=$ never to $4=$ very often) (Diekstra et al., 1991). Because of high interrelations (ranging from .29 to .73), an exploratory factor analysis was conducted with the four scores as variables. A single-factor solution was obtained, explaining $58.8 \%$ of the total variance at the first wave; loadings were .60 and higher (see also Helsen, Vollebergh, \& Meeus, 2000). Each adolescent was thus assigned one factor score for the construct of emotional problems.

Relationship status was assessed by three items at each wave. The first item asked whether the respondent had a best friend. In all three waves all respondents gave a positive answer to this item. The second item asked whether the respondents had an intimate partner. The number of respondents with an intimate partner ranged between 475 in Wave 1 to 775 in Wave 3 (35\% and $59 \%$, respectively). The third item asked which individual the respondent considered to be the most important person in his/her life at the moment. Respondents could make the choice between best friend or intimate partner. It is of importance to note that respondents with an intimate partner systematically nominated the intimate partner as the most important person. 
Table 1

Relationship status by age

\begin{tabular}{|c|c|c|c|c|}
\hline \multirow[b]{2}{*}{ Age in wave 1} & \multicolumn{4}{|c|}{ Relationship status } \\
\hline & $\begin{array}{c}\text { Systematic intimate } \\
\text { partner experience } \\
\text { (Sipe) }\end{array}$ & $\begin{array}{l}\text { Best friend to } \\
\text { intimate partner } \\
\text { (Bf-Ip) }\end{array}$ & $\begin{array}{c}\text { Best friend } \\
\quad(B f-B f)\end{array}$ & No pattern \\
\hline \multicolumn{5}{|c|}{ Adolescents, aged $12-20$} \\
\hline $12-14$ & 16 & 91 & 140 & 28 \\
\hline $15-17$ & 50 & 112 & 109 & 36 \\
\hline $18-20$ & 91 & 59 & 56 & 13 \\
\hline Total & 157 & 262 & 305 & 77 \\
\hline \multicolumn{5}{|c|}{ Young adults, aged $21-23$} \\
\hline $21-23$ & 234 & 38 & 45 & 7 \\
\hline Grand total & 391 & 300 & 350 & 84 \\
\hline
\end{tabular}

Twelve hundred and forty-five of the 1302 respondents had a valid score on the third item in all three waves. The yes-no answers to this question across the three waves could be categorized in four patterns. (1) Systematic intimate partner experience group (Sipe): respondents who nominated the intimate partner as the most important person in all three waves or in Waves 1 and 3, and consequently had experience with one or more intimate partners for a period that spanned, although not necessarily continuously, a period of six years. (2) Best friend to intimate partner group (Bf-Ip): respondents who nominated a best friend as the most important person in Wave 1 and the intimate partner as the most important person in Wave 3. (3) Best friend group (Bf-Bf): respondents who nominated the best friend at all three waves as the most important person, and did not have an intimate partner. (4) No pattern group: respondents who did not nominate an intimate partner in Wave 3 and only nominated a best friend or intimate partner in one or two of the other waves.

To test the early adult saliency perspective, we will use two age categories within these groups: adolescents aged 12-20 in Wave 1, and young adults aged 21-23 in Wave 1. Since we collapsed the adolescents in one group in our analyses, we checked whether there were, within the three relationships status groups, differences between early, middle and late adolescents in mean change over time of the study variables, as well as in correlations of the study variables at Wave 1 and Wave 3. Repeated measure MANOVA's revealed no differences in mean change between the adolescent groups $\left(F_{\mathrm{s}}<\right.$ 1.1 ), while pairwise comparisons of the correlations of the adolescent groups revealed a significant difference in 3 out of 54 comparisons only. So, by collapsing them we did not obscure differences between the adolescent groups. The no pattern group will be left out of the analyses, since it is not possible to designate this group as a group with partner, moving into partnership, or with best friend. Leaving out this group $(n=84)$ and cases with missing values reduced the sample size to 1041 . Table 1 gives the numbers for each of the groups.

\section{Results}

To test hypotheses 1 and 2, two repeated measure MANOVA's were completed with relational commitment and emotional problems as within-subjects factors, relationship status and age-group as between-subjects factors, and gender and educational level as co-variates.

Saliency of intimate partner and best friend. The first MANOVA revealed significant longitudinal change of relational commitment, main effects of relationship status, gender and educational level, and a significant longitudinal change of relational commitment by relationship status interaction. Relational commitment showed an increase over time, $F(1,033)=12.04, p<.001$, proved to be stronger in the Sipe group than in the Bf-Ip and in the Bf-Bf group, $F(2,033)=$ $125.04, p<.001$, stronger in females than in males, $F(1,1033)$ $=22.89, p<.001$, and stronger in lower educated subjects than in higher educated subjects, $F(1,1033)=13.60, p<.001$. No main effect of age category was found, $F(1,1033)=.36, p>$ .05. The interaction of longitudinal change of relational commitment by relationship status, $F(2,1033)=24.99, p<$ .001 , revealed that over time, relational commitment was stronger in the Sipe group than in the Bf-Bf group, and increased in the Bf-Ip group from a level near to that of the $\mathrm{Bf}-\mathrm{Bf}$ group at $\mathrm{T} 1$ to a level near to that of the Sipe group at T3. No interaction of longitudinal change of relational commitment by relationship status by age category was found, $F(2,1033)=.96, p>.05$. Taken together, the over-time change of relational commitment was not different between the age categories within the three relationship groups. These findings support hypothesis 1, derived from the general saliency perspective: relational commitment grows when adolescents and early adults make the transition from best friend to intimate partner as most important person. Figure 1 shows the interaction of longitudinal change of relational commitment (estimated marginal means) by relationship status.

Having a best friend and/or intimate partner and emotional adjustment. The second MANOVA revealed only one significant effect: a longitudinal change of emotional problems by relationship status interaction, $F(1,1033)=4.00, p<.05$. No 


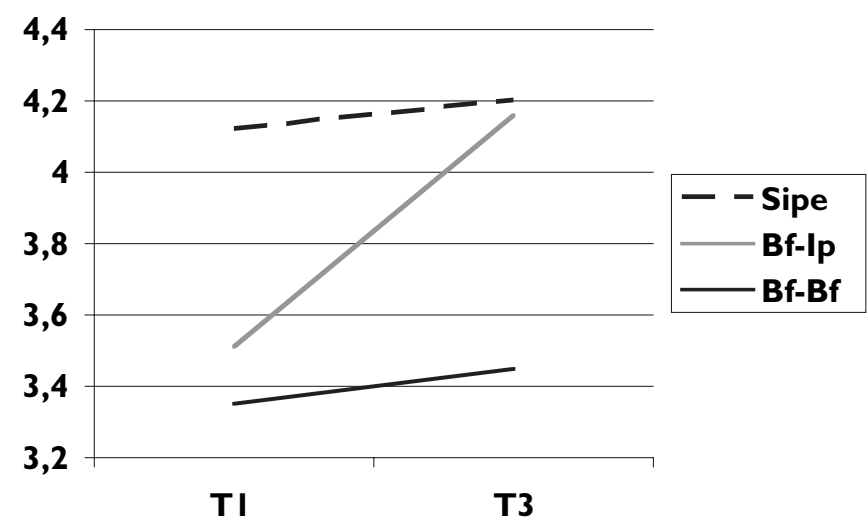

Figure 1. The interaction of longitudinal change of relational commitment by relationship status.

other main effects nor interaction of longitudinal change of emotional adjustment by relationship status by age category was found. The disordinal interaction showed that in the Sipe and Bf-Ip group emotional problems decreased over time, whereas in the Bf-Bf group problems increased (see Figure 2). The interaction does not support Hypothesis 2, derived from the early adult saliency perspective. Having or getting an intimate partner does not only cause less problems over time in early adults but also in adolescents. The findings, however, are not inconsistent with the general saliency perspective.

\section{Linking quality of relationships to emotional problems and relationships to relationships: Longitudinal models}

Multi-group models. To test Hypotheses 3 to 6 we used data from Waves 1 and 3 to specify a series of longitudinal models. Since the early adult saliency perspective predicts not only effects of relationship status, but also age differences in these effects, we used a a six group multigroup model, Sipe/12-20, Sipe/21-23, Bf-Ip/12-20, Bf-Ip/21-23, Bf-Bf/12-20, and Bf$\mathrm{Bf} / 21-23$, and tested which model fitted best for the six groups in several multigroup analyses using AMOS. Figures $3 a-3 c$ show the models for the different groups. For reasons of presentation, we show one figure for each relationship status group, nested within each relationship status group are the two age groups. The covariance matrices of the six groups were

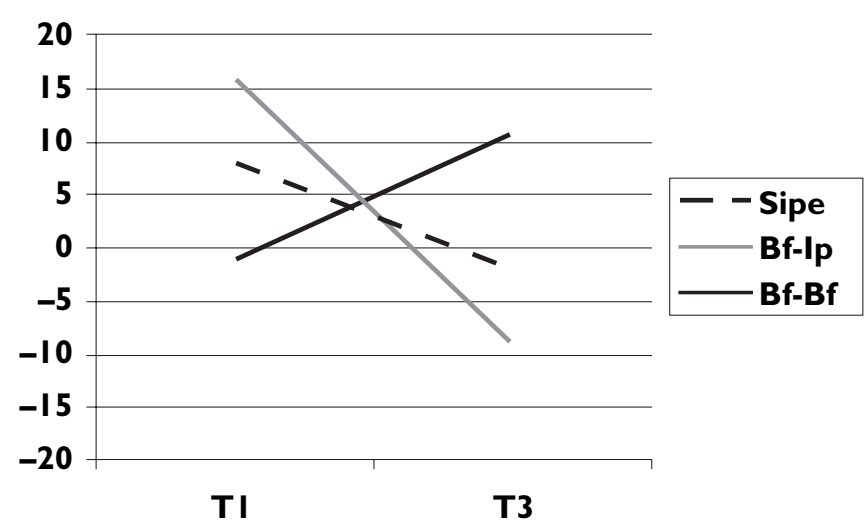

Figure 2. The longitudinal change of emotional problems by relationship status interaction. used as input for the structural equation models. In all models we included gender and educational level as control variables.

To study our hypotheses, we tested a series of models against each other. We started with a restricted model, in which all the estimated parameters were required to be equal across groups. The restricted model was followed up by a series of less restricted models. Set 1 of these models tested Hypotheses 3 and 4: $\mathrm{T} 1$-associations were allowed to differ across groups. In Set 2 stability paths were allowed to differ. In Set 3 cross-paths were allowed to differ, and in Set 4 T3-associations were allowed to differ. The chi-square difference test was used to determine which model best represents the data. When the chisquare difference test did not show a difference between the models, the more parsimonious model, that is, the model that required less specifications of between group differences, was considered to be the best model (Duncan, Duncan, Strycker, $\mathrm{Li}$, \& Alpert, 1999). The best model from each set was used as a starting model in the next set of models. Table 2 presents the model comparisons. Critical ratio tests for differences between parameters were used to assess whether paths were different for groups.

Quality of relationships and emotional adjustment (Hypothesis 3) and linkage between parents and intimate partner (Hypothesis 4). In the first set of analyses Hypotheses 3 and 4 were tested by comparing Models $1 \mathrm{a}, 1 \mathrm{~b}$ and the restricted model with each other. Model 1a contained T1 specifications in accordance with the early adult saliency perspective whereas Model $1 \mathrm{~b}$ was specified according to the general saliency perspective. In Model 1a all T1-correlations were specified to be different between Sipe/21-23 and the other groups, whereas in Model $1 \mathrm{~b}$ the T1-correlations were specified to be different between both Sipe groups on the one hand and the four other groups. Table 2 shows that Model 1a fitted the data better than the restricted model, while Model $1 \mathrm{~b}$ did not provide a better fit than Model 1a. Lifting three more restrictions in this model did not improve the fit as compared to Model 1a. So, Model $1 \mathrm{a}$ is the more parsimonious and superior model. Model 1a supports Hypotheses 3 and 4 regarding the cross-sectional associations at $\mathrm{T} 1$. In the older Sipe group the T1 associations between relational commitment and emotional problems (Hypothesis 3), and between relational commitment and parental support (Hypothesis 4) are stronger than in the 5 other groups. Critical ratios were $4.23, p<.001$ and $3.10, p<$ .01 , respectively. These findings are in full agreement with early adult saliency perspective Hypotheses 3 and 4. Relational commitment to intimate partner has a stronger negative association with emotional problems in early adulthood (Sipe2) than in adolescence (Sipe1), and relational commitment to intimate partner in early adulthood (Sipe2) is more strongly associated with emotional problems than relational commitment to best friend in early adulthood (Bf-Ip2, Bf-Bf2) and adolescence (Bf-Ip1, Bf-Bf1). The same goes for the association between relational commitment and parental support. Table 3 and Figures $3 \mathrm{a}$ to $3 \mathrm{c}$ show the parameter estimates for the six groups.

Stability of relational commitment (Hypothesis 5), and bestfriend-intimate partner linkage (Hypothesis 6). In Set 2 of model comparisons, Hypothesis 5 was tested by comparing Models 2a and 1a and 2a and 2b. Model 2a contained specifications in accordance with the early adult saliency perspective: the six year stability of relational commitment to intimate partner was specified to be different between Sipe/21-23 and 
(a)

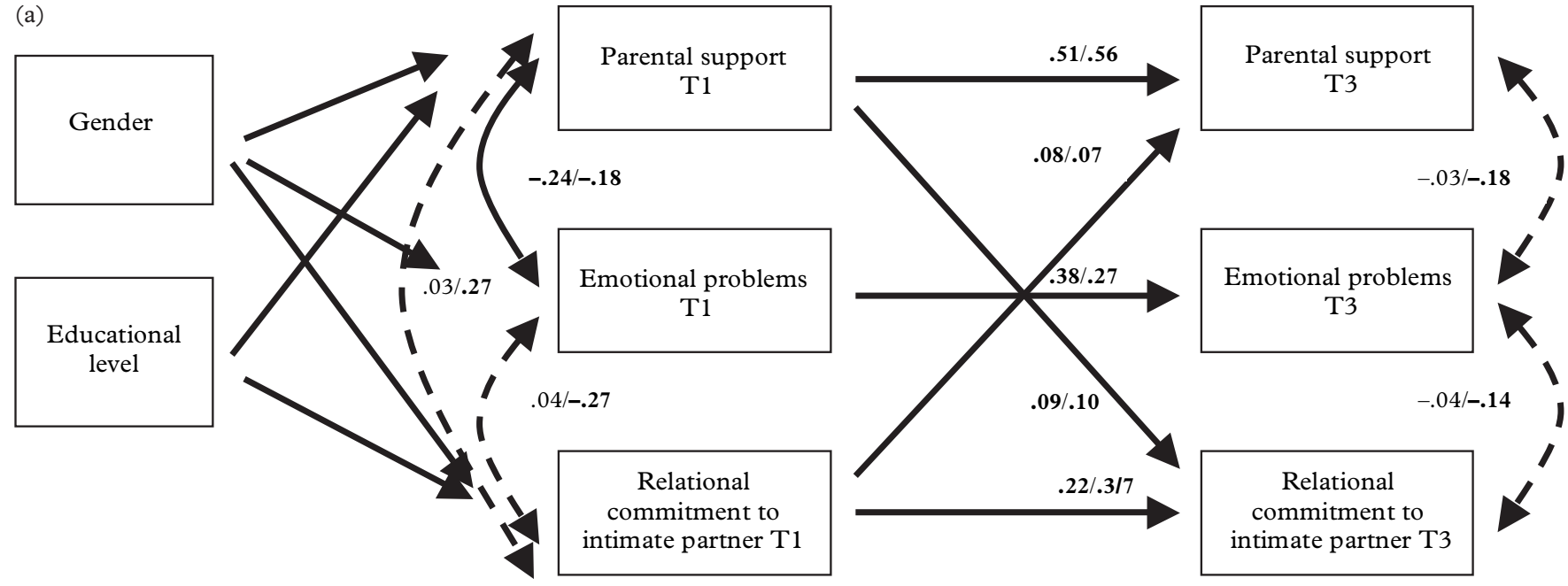

(b)

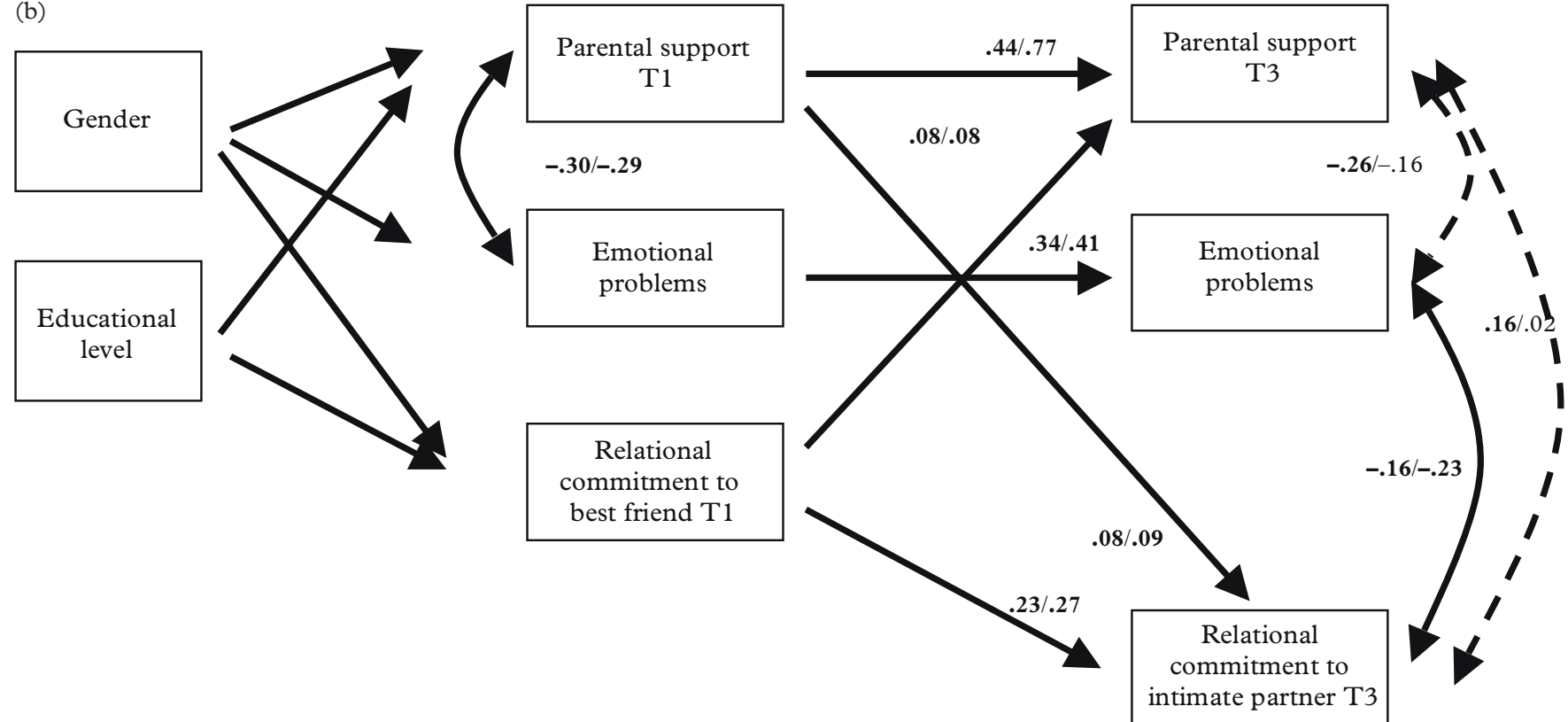

(c)

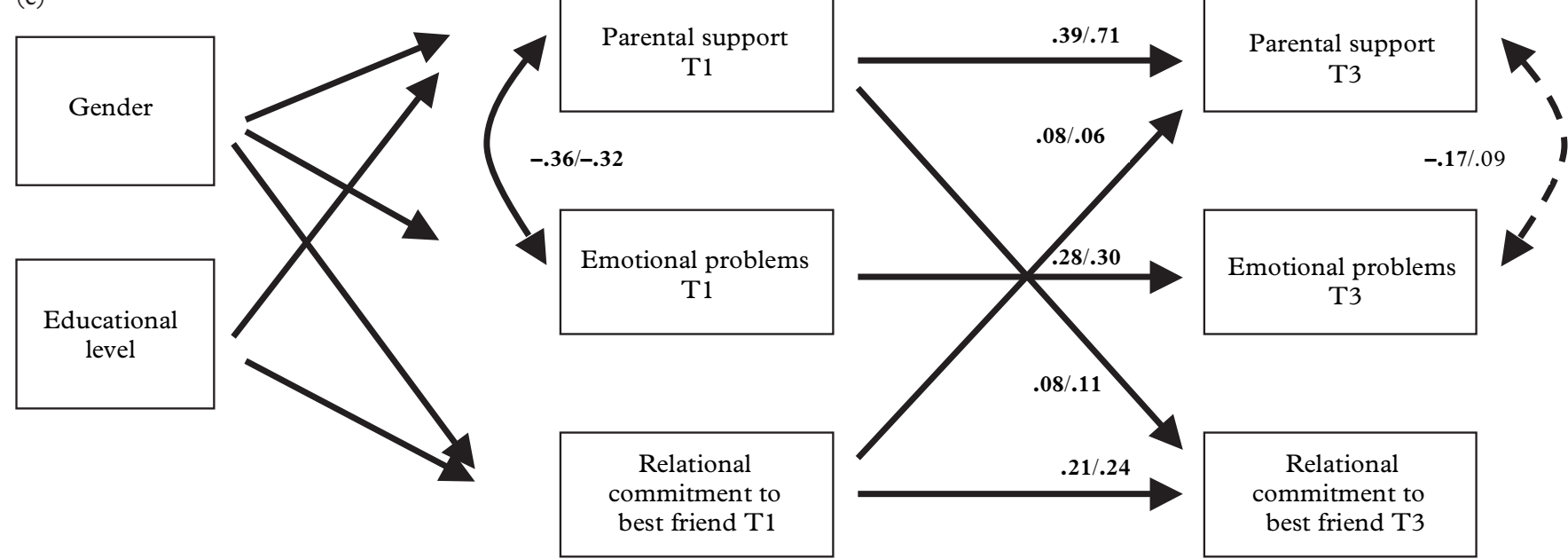

Figures 3a-c. Models for the systematic intimate partner experience groups (a), the best friend to intimate partner groups (b), and the best friend-best friend groups (c). Statistics of the relevant significant parameters of both age groups within the relationship status groups are printed. The first statistic is that of the youngest group, the second that of the oldest. Only significant estimates are shown. Broken lines indicate correlations or paths that were significant in only one group. 
Table 2

Model comparisons

Model comparison tests

\begin{tabular}{|c|c|c|c|c|c|c|}
\hline \multirow[b]{2}{*}{ Model (test of hypotheses) } & \\
\hline & Models & $\chi^{2}$ & $d f$ & $\Delta \chi^{2}$ & $\Delta d f$ & $\mathrm{p}(d)$ \\
\hline 0 . Restricted model: All groups similar & 0 & 236.84 & 147 & & & \\
\hline \multicolumn{7}{|l|}{ Set 1 . T1-associations different across groups } \\
\hline 1a. IP early adult saliency perspective (hypotheses 3 and 4) & $1 \mathrm{a}-0$ & 207.97 & 144 & 31.82 & 3 & $p<.001$ \\
\hline 1b. IP general saliency perspective (hypotheses 3 and 4) & $1 \mathrm{~b}-1 \mathrm{a}$ & 205.02 & 141 & 2.95 & 3 & $p>.05$ \\
\hline \multicolumn{7}{|l|}{ Set 2 . Stability paths different across groups } \\
\hline $\begin{array}{l}\text { 2a. IP early adult saliency perspective: Model } 1 \mathrm{a}+\text { relational commitment } \\
\text { in Sipe/21-23 more stable (hypotheses } 5 \text { and } 6 \text { ) }\end{array}$ & $2 \mathrm{a}-1 \mathrm{a}$ & 203.08 & 143 & 4.89 & 1 & $p<.05$ \\
\hline $\begin{array}{l}\text { 2b. IP general saliency perspective: Model } 1 \mathrm{a}+\text { relational commitment in } \\
\text { Sipe/12-20 and } 21-23 \text { more stable (hypotheses } 5 \text { and } 6 \text { ) }\end{array}$ & $2 \mathrm{~b}-2 \mathrm{a}$ & 203.06 & 142 & .02 & 1 & $p>.05$ \\
\hline 2c. Model 2a + stability parental support different across groups & $2 \mathrm{c}-2 \mathrm{a}$ & 185.06 & 138 & 18.02 & 5 & $p<.01$ \\
\hline \multicolumn{7}{|l|}{ Set 3. Cross-paths different across all groups } \\
\hline 3. Model $2 c+$ all cross-paths free across groups & $3-2 c$ & 147.68 & 108 & 37.39 & 30 & $p>.05$ \\
\hline \multicolumn{7}{|l|}{ Set 4. T3-correlations different across groups } \\
\hline 4a. Model $2 c+$ all T3 correlations different across groups & $4 a-2 c$ & 154.32 & 123 & 30.74 & 15 & $p<.01$ \\
\hline $\begin{array}{l}\text { 4b. Model } 2 \mathrm{c}+\mathrm{T} 3 \text { correlations relational commitment }- \text { emotional } \\
\text { problems different across two sets of groups }\end{array}$ & $4 \mathrm{~b}-4 \mathrm{a}$ & 156.02 & 127 & 1.70 & 4 & $p>.05$ \\
\hline
\end{tabular}

Sipe/12-20, and aditionally to be different from stability of relational commitment in the the other four groups (Hypothesis 5). Model 2b was specified in accordance with the general saliency perspective: the stability of relational commitment was specified to be different between both Sipe groups and the other four groups. Table 2 shows that Model $2 \mathrm{a}$ fitted the data better than Model 1a, whereas Model $2 \mathrm{~b}$ did not provide a better fit than Model 2a. Lifting one more restriction in this model did not improve the fit as compared to Model 2a. So Model 2a proved to be the better model. Model 2a shows that in the older Sipe group the stability of relational commitment was significantly bigger than in the other five groups; critical ratio was 2.05, $p<.05$. These findings support early adult saliency Hypothesis 5: in early adulthood (Sipe2) the stability of relational commitment to intimate partner is larger than in adolescence (Sipe1). Additionally, Model 2a reveals that the stability of relational commitment to intimate partner in early adulthood was larger than the stability of relational commitment to best friend in early adulthood (Bf-Bf2) and adolescence (Bf-Bf1), and also, quite obviously, larger than the linkage between relational commitment to best friend and intimate partner in early adulthood (Bf-Ip2) and adolescence (Bf-Ip1).

The test of Hypothesis 6 was included in Models 2a and $2 b$.We expected to find a significant six year link between relational commitment to best friend and relational commitment to intimate partner. Please note that in technical terms we tested the stability path between relational commitment to best friend and relational commitment to intimate partner; conceptually however, this path is not a stability path but a relationship linkages path. The findings of model 2a support Hypothesis 6. In both BF-Ip groups a significant linkage was found between relational commitment to best friend and intimate partner: so in adolescence and early adulthood relational commitment to best friend predicts relational commitment to intimate partner six years later. Additionally, we improved in Set 2 the model fit by setting free the stability of parental support between groups (Model 2c).
In Set 3 of model comparisons, we tested whether the groups showed differences in cross-lagged paths between the study variables. Table 2 shows that Model 3 did not fit the data better than Model 2a. So, no systematic differences in crosspaths between the six groups were found. Table 3 shows that most of the cross-paths were non significant. The table also reveals small bi-directional influences over time between parental support and relational commitment in all groups. Finally, we tested in the fourth set of models whether the groups differed in $\mathrm{T} 3$ associations between the study variables. Significant T3 associations are to be interpreted as correlated change (Neyer \& Asendorf, 2001). Emerging after controlling for $\mathrm{T} 1$ associations, stability paths, and cross paths, they indicate that over time change of one variable is correlated to change in another variable. Table 2 shows that Model $4 \mathrm{a}$ fitted the data better than Model 2c: the six groups differ in correlated change of the study variables. The most important finding that emerged from inspection of the model parameters was that the correlated change between relational commitment and emotional problems was significant in the older Sipe group and both Bf-Ip groups and not in the other three groups. Therefore we specified Model $4 \mathrm{~b}$ in which the T3 associations were constrained to be equal in the older Sipe group and both $\mathrm{Bf}-\mathrm{Ip}$ groups on the one hand, and in the younger Sipe group and both Bf-Bf groups on the other hand. This model had four restrictions less than Model $4 \mathrm{a}$ and was found to have the same fit. So, Model $4 \mathrm{~b}$ is the more parsimonious and superior model. Inspection of the model parameters (see Table 3 and Figures $3 \mathrm{a}$ to $3 \mathrm{c}$ ) revealed that the correlated change between relational commitment was larger in the older Sipe group and both Bf-Ip groups than in the other three groups: critical ratio was $3.00, p<.01$. These findings show that increase of relational commitment to intimate partner is associated with decrease of emotional problems in early adulthood, and increase of relational commitment is associated with decrease of emotional problems in subjects who move from best friend to intimate partner as most important person in early adulthood (Bf-Ip2), and in the 
Table 3

Standardized maximum-likelihood estimates and fit coefficients of model $4 b^{1,2}$

\begin{tabular}{|c|c|c|c|c|c|c|}
\hline \multirow[b]{3}{*}{ Parameter } & \multicolumn{6}{|c|}{ Age group by relationship status group } \\
\hline & \multicolumn{3}{|c|}{$12-20$} & \multicolumn{3}{|c|}{$21-23$} \\
\hline & $\begin{array}{c}\text { Sipe1 } \\
\mathrm{n}=157\end{array}$ & $\begin{array}{c}B f-I p 1 \\
\mathrm{n}=262\end{array}$ & $\begin{array}{c}B f-B f 1 \\
\mathrm{n}=305\end{array}$ & $\begin{array}{c}\text { Sipe2 } \\
\mathrm{n}=234\end{array}$ & $\begin{array}{l}B f-I p 2 \\
\mathrm{n}=38\end{array}$ & $\begin{array}{l}B f-B f 2 \\
\mathrm{n}=45\end{array}$ \\
\hline \multicolumn{7}{|l|}{ Exogenous variables $-\mathrm{T} 1$ variables } \\
\hline Educational level - Relational commitment $\mathrm{T} 1$ & $-.10^{\star \star \star}$ & $-.10^{\star \star \star}$ & $-.11^{\star \star \star}$ & $-.11^{\star \star \star}$ & $-.09^{\star \star \star}$ & $-.12^{\star \star \star}$ \\
\hline Educational level - Parental support T1 & $-.08^{\star \star}$ & $-.09^{\star \star}$ & $-.09^{\star \star}$ & $-.08^{\star \star}$ & $-.09^{\star \star}$ & $-.12^{\star \star}$ \\
\hline Educational level - Emotional problems T1 & -.02 & -.02 & -.03 & -.02 & -.02 & -.03 \\
\hline Gender - Relational commitment T1 & $.14^{\star \star \star}$ & $.14^{\star \star \star}$ & $.15^{\star \star \star}$ & $.15^{\star \star \star}$ & $.14^{\star \star \star}$ & $.18^{\star \star \star}$ \\
\hline Gender - Parental support T1 & $.07^{\star \star}$ & $.08^{\star \star}$ & $.09^{\star \star}$ & $.07^{\star \star}$ & $.09^{\star \star}$ & $.08^{\star \star}$ \\
\hline Gender - Emotional problems T1 & $-.12^{\star \star \star}$ & $-.13^{\star \star \star}$ & $-.16^{\star \star \star}$ & $-.14^{\star \star \star}$ & $-.13^{\star \star \star}$ & $-.16^{\star \star \star}$ \\
\hline \multicolumn{7}{|l|}{$\mathrm{T} 1$ correlations } \\
\hline Relational commitment T1 - Emotional problems T1 & $.044_{b}$ & $.05_{b}$ & $.06_{b}$ & $-.27 \mathrm{a}^{\star \star \star}$ & $-.04 \mathrm{~b}$ & $.07_{\mathrm{b}}$ \\
\hline Parental support T1 - Emotional problems T1 & $-.24^{\star \star \star}$ & $-.30 \star \star \star$ & $-.36^{\star \star \star}$ & $-.18^{\star \star \star}$ & $-.29 \star \star \star$ & $-.32^{\star \star \star}$ \\
\hline Parental support T1 - Relational commitment T1 & $.03_{\mathrm{b}}$ & $.03_{\mathrm{b}}$ & $.03_{\mathrm{b}}$ & $.27_{\mathrm{a}}^{\star \star \star}$ & $.03 \mathrm{~b}$ & $.03_{\mathrm{b}}$ \\
\hline \multicolumn{7}{|l|}{ Stability paths } \\
\hline Relational commitment $\mathrm{T} 1-\mathrm{T} 3$ & $.22 b_{b}^{\star \star \star}$ & $.23 \mathrm{~b}$ & $.21_{b} b^{\star \star \star}$ & $.37 \mathrm{a}^{\star \star \star}$ & 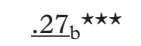 & $.24 b_{b}^{\star \star \star}$ \\
\hline Parental support $\mathrm{T} 1-\mathrm{T} 3$ & $.51^{\star \star \star}$ & $.43^{\star \star \star}$ & $.39^{\star \star \star}$ & $.56^{\star \star \star}$ & $.77^{\star \star \star}$ & $.71^{\star \star \star}$ \\
\hline Emotional problems $\mathrm{T} 1-\mathrm{T} 3$ & $.38^{\star \star \star}$ & $.34^{\star \star \star}$ & $.28^{\star \star \star}$ & $.27^{\star \star \star}$ & $.41^{\star \star \star}$ & $.30^{\star \star \star}$ \\
\hline \multicolumn{7}{|l|}{ Cross-lagged paths } \\
\hline Relational commitment T1 - Parental support T3 & $.08^{\star \star}$ & $.08^{\star \star}$ & $.08^{\star \star}$ & $.07^{\star \star}$ & $.08^{\star \star}$ & $.06^{\star \star}$ \\
\hline Parental support $\mathrm{T} 1$ - Relational commitment $\mathrm{T} 3$ & $.09^{\star \star}$ & $.08^{\star \star}$ & $.08^{\star \star}$ & $.10^{\star \star}$ & $.09^{\star \star}$ & $.11^{\star \star}$ \\
\hline Emotional problems T1 - Parental support T3 & -.02 & -.02 & -.02 & -.02 & -.02 & -.02 \\
\hline Parental support T1 - Emotional problems T3 & -.02 & -.02 & -.02 & -.02 & -.02 & -.03 \\
\hline Relational commitment T1 - Emotional problems T3 & .03 & .03 & .03 & .03 & .04 & .03 \\
\hline Emotional problems T1 - Relational commitment T3 & .05 & .04 & .04 & .04 & .05 & .05 \\
\hline \multicolumn{7}{|l|}{ T3 correlations } \\
\hline Relational commitment T3 - Emotional problems T3 & $-.04_{\mathrm{b}}$ & $-.16 \mathrm{a}^{\star \star \star}$ & $-.06_{b}$ & $-1.5_{a}^{\star \star \star}$ & $.23{ }_{\mathrm{a}}^{\star \star \star}$ & $.09_{\mathrm{b}}$ \\
\hline Parental support T3 - Emotional problems T3 & -.03 & $-.26^{\star \star \star}$ & $-.17^{\star \star}$ & $-.18^{\star \star}$ & -.16 & .09 \\
\hline Parental support T3 - Relational commitment T3 & .05 & $.16^{\star \star}$ & .05 & .03 & .02 & .16 \\
\hline \multicolumn{7}{|l|}{ Fit coefficients } \\
\hline$\chi^{2}$ & \multicolumn{6}{|c|}{156.02} \\
\hline $\mathrm{df}$ & \multicolumn{6}{|c|}{127} \\
\hline GFI & \multicolumn{6}{|c|}{.96} \\
\hline RMSEA & \multicolumn{6}{|c|}{.02} \\
\hline
\end{tabular}

Notes.

${ }^{1}$ Estimates supporting the IP early adult saliency perspective are underlined.

2 Underlined estimates sharing a common subscript across columns are not significantly different from each other.

${ }^{\star} p<.05 ;{ }^{\star \star} p<.01 ;{ }^{\star \star \star} p<.001$.

transition from adolescence to early adulthood (Bf-Ip1, mean age at T3 was 21.6 years). These findings are consistent with the early adult saliency perspective.

\section{Discussion}

This study concentrated on the intimate partner relationship of adolescents and early adults. We tested a series of hypotheses derived from the general saliency perspective and the early adult saliency perspective. The general saliency perspective predicts that the intimate partnership is a developmentally and psychologically more salient relationship than the best friend relationship in adolescence and in early adulthood. The early adult saliency perspective entails that the intimate partner relationship becomes more salient in early adulthood than in adolescence, and only becomes more psychologically salient than the best friend relationship in early adulthood. To test the hypotheses derived from both perspectives, we studied the shift from best friend to intimate partner as most important peer and examined links between relationships and emotional problems as well as links between relationships themselves.

As for the psychological significance of best friend and intimate partner we found support for the general saliency perspective. As predicted, relational commitment increases over time when adolescents and early adults make the shift from best friend to intimate partner. Also, contrary to our hypothesis but supportive of the general saliency perspective, in early adulthood as well as in adolescence the shift to intimate partner went hand in hand with a decrease of emotional problems. So, when early adults and adolescents make the shift from best friend to intimate partner, relational commitment becomes stronger and emotional problems become smaller. As for emotional problems our findings differ from earlier studies 
(Brendgen et al., 2002; Joyner \& Udry, 2000; Meeus et al., 2004; Neeman et al., 1995; Zimmer-Gembeck et al., 2001) showing that the transition to intimate partner only in adolescence leads to more problematic behavior. This could be due to the fact that the adolescents in our sample (mean age was 17.7) were older than the adolescents in the earlier mentioned studies.

Our models on the links between relationships and emotional problems and relationships themselves clearly support Hypotheses 3, 4, and 5, all derived from the early adult saliency perspective. Hypothesis 3 predicted that stronger relational commitment to intimate partner would go hand in hand with less emotional problems in early adulthood at Time 1. Relational commitment to intimate partner in adolescence and to best friend in adolescence and early adulthood was not expected to be associated with emotional problems. We found the hypothesized pattern at Time 1 , and also the findings at Time 3 were in agreement with the early adult saliency perspective. Analyses of the correlated change of relational commitment and emotional problems showed that growth of relational commitment was associated with a decline of emotional problems over time in early adults with an intimate partner (Sipe2) and adolescents and early adults who acquired an intimate partner at Time 3 (Bf-Ip1 and Bf-Ip2). So, when early adults have an intimate partner or acquire an intimate partnership in early adulthood, growth of relational commitment goes together with a decline of emotional problems. The same goes for adolescents who acquire an intimate partnership in the transition from adolescence to early adulthood. Since in our sample the Bf-Ip1 group had a mean age of 15.6 years at Time 1 and 21.6 at Time 3, the findings for this group are also consistent with the early adult saliency perspective. Also, the findings that level of relational commitment to intimate partner was not linked to emotional problems in adolescence (Sipe1) and that relational commitment to best friend was not linked to emotional problems in adolescence (Bf-Bf1) and early adulthood (Bf-Bf2) were consistent with the early adult saliency perspective. And finally, the finding that growth of relational commitment to intimate partner was not associated with a decline of emotional problems in adolescents with systematic intimate partner experience (Sipe1) was consistent with the early adult saliency perspective. This group reached early adulthood at Time 3 as well, but the correlated change between relational commitment to intimate partner and emotional problems was not significant. These findings suggest that the relationship with intimate partner may not become psychologically mature and salient in early adulthood in adolescents who start relatively early to engage with an intimate partner. Here again we have an indication of the negative side of relatively early intimate partnership. Various studies (Brendgen et al., 2002; Joyner \& Udry, 2000; Meeus et al., 2004; Neeman et al., 1995; Zimmer-Gembeck et al., 2001) found that early intimate relationships lead to depression. We find that the quality of the early intimate relationship does not go hand in hand with better emotional adjustment.

Hypothesis 4 predicted that at $\mathrm{T} 1$ the link between relational commitment to intimate partner and parental support would be larger in early adulthood than in adolescence. Full support for the hypothesis was found. Additionally we found that the link between relational commitment to intimate partner and parental support in early adulthood was stronger than between relational commitment to best friend and parental support in early adulthood and adolescence. At Time 1, only in early adulthood and not in adolescence the link between relational commitment to intimate partner and parental support was significant. Neither in the adolescent (Bf-Ip1, Bf-Bf1) nor in the early adult groups (Bf-Ip2, Bf-Bf2) was a link between relational commitment to best friend and parental support found. While these findings support the earlt adult saliency perspective again, the results at Time 3 do not. The parameters of the correlated change of relational commitment and parental support did not show a consistent picture. These findings suggest a temporary link between relational commitment to intimate partner and parental support. We will come back to this issue.

Taken together these findings clearly support the early adult saliency perspective. Only in early adulthood and not in adolescence a stronger commitment to intimate partner went hand in hand with less emotional problems, and more parental support was found to be linked to stronger relational commitment to intimate partner. Also, we found support for Hypothesis 5. Relational commitment to intimate partner was more stable than relational commitment to best friend in early adulthood but not in adolescence. So, the relationship with intimate partner is psychologically more salient and therefore more stable in early adulthood than in adolescence, and also more significant than that with best friend in early adulthood and adolescence.

Why does the psychological meaning of the intimate partner become salient in early adulthood? Normative developmental patterns seem to offer an explanation here. In nowadays' western societies early adulthood is the critical period of the formation of stable intimate relationships. More than adolescents, early adults are looking for a partner with whom they will spend a substantial part of later life. More than adolescents, they are tuned to finding the attachment value of an intimate partner. Therefore in early adulthood, the quality of relationship with intimate partner stabilizes and becomes more linked to emotional adjustment and the relation with parents. However, our findings suggest that the link between quality of relation with best partner and emotional adjustment is a stable one whereas the link between parental support and the intimate partnership is temporarily. The first link was found at Time 1 and Time 3, while the second link only was found at Time 1 . These results suggest a potential reinterpretation of attachment theory and the function of working models (Bowlby, 1969; Furman et al., 2002). They indicate, as also was suggested by Collins and Laursen (2000), that only in early adulthood does the working model of the earlier parent-adolescent relation, in this case parental support, become activated and function as a mirror of the later relationship with an intimate partner. This activation of the working model seems to function as a sort of a temporarily check of the quality of the relationship with the intimate partner, and not as a lasting one. Two of our findings are in agreement with this idea of temporarily activation of working models. If a relation is not psychologically salient, such as the relation with best friend, the working model is not activated. We indeed did not find a link between parental support $\mathrm{T} 1$ and relational commitment to best friend $\mathrm{T} 1$ in both Bf-Ip and both Bf-Bf groups. Also, in adolescence, when the relationship with intimate partner is not psychologically mature and salient, the working model is not activated. Indeed, we did not find a link between parental support $\mathrm{T} 1$ and relational commitment to intimate partner T1 in the Sipe1 group. Additional support for our interpretation can be derived from the comparison of the 
correlation between parental support $\mathrm{T} 1$ and relational commitment to intimate partner $\mathrm{T} 1$ in the Sipe/21-23 group and the cross-path between parental support $\mathrm{T} 1$ and relational commitment to intimate partner and best friend $\mathrm{T} 3$ in all the groups. The estimates were -.27 and between .09 and .11 respectively (see Table 3 ) and differed significantly; critical ratio was $3.90, p<.001$. So, although earlier parental support predicts later relational commitment somewhat, especially in early adulthood, the link between parental support and relational commitment to intimate partner becomes substantial.

Our findings also shed new light in the meaning of friendships in adolescence and early adulthood. In none of the groups was an association found between quality of friendship with best friend and emotional adjustment. Obviously, best friends are not that important for emotional well being. This could be due to the fact that friendships often change in adolescence and early adulthood. Recent studies (Bowker, 2004; Değirmencioğlu, Urberg, Tolson, \& Richard, 1998) showed that only half of close or reciprocal friendships keep stable across one year. Obviously, non-stable relationships cannot protect against emotional problems. However, one has to keep in mind that we used a very specific measure of the relationship quality with best friend: relational commitment. Other aspects of relationship quality with best friends were found to be systematically linked to emotional adjustment. For instance, Kuttler, La Greca, and Prinstein (1999) found significant associations between social competence in friendships and internalising and externalising problems.

Finally, we found support for Hypothesis 6. Relational commitment to best friend was found to be predictive of relational commitment to intimate partner six years later. This finding supports the idea that skills of egalitarian relationships are learned in the best friend relationship and generalize to the intimate partner relationship (Connolly \& Johnson, 1996; Furman \& Wehner, 1994; Scharf \& Mayseless, 2001).

In sum, our results suggest the following patterns of the development of personal relationships in adolescence and early adulthood. When adolescents and early adults make the transition to the intimate partnership they enter a psychological more meaningfull relationship. When individuals enter early adulthood the psychological value of the intimate partner relationship becomes more salient: the quality of the intimate relationship becomes more stable and linked to emotional adjustment.

\section{Issues and limitations}

In general we found small effect sizes in our empirical study (Cohen, 1992). An explanation for this could be that we presented data from a representative national sample. We have therefore had to work with the small differences that are found in a general population, and not the more powerful differences that are obtained by, for instance, comparing contrast groups. In this connection, we concur with the observation of Prentice and Miller (1992) that small effects can be impressive if they are of major theoretical importance; and we have shown that several of our data are new and theoretically significant.

Although we could use a big sample in this study, we were unable to test whether the links between relational commitment and emotional adjustment and between relationships themselves were different for the four phases of romantic relationships as proposed by Brown (1999). This would have required a multi-group model with 12 groups (four age groups $\times$ three relationship status groups) which simply is not feasible.

Finally, when interpreting the results, it is important to bear in mind that all the concepts used in the present study were assessed by the self-report method. This means that when we refer to, for instance, parental support, we are speaking of the adolescents' perception of the support offered by parents. The parents themselves gave no information on parental support. Consequently, the finding that parental support is linked to emotional adjustment, for instance, represents the view of the adolescents and not that of their parents. Common method variance, the tendency of subjects to respond to different questions in the same way, is a threat to the validity of self-reports. However, we think it to be quite unlikely that our results could be explained by common method variance. The main findings of our study are that the associations between the study variables are different for the six groups we distinguished. It is almost impossible to explain these findings in terms of common method variance. Such an explanation would have to assume that common method variance takes effect differently in the six groups. We think it quite unlikely for such a common method variance by group interaction to occur.

\section{References}

Armsden, G., \& Greenberg, M. (1987). The inventory of parent and peer attachment: Individual differences and their relationship to psychological well-being in adolescence. Fournal of Youth and Adolescence, 16, 427-453.

Block, J., \& Kremen, A. (1996). IQ and ego-resiliency: Conceptual and empirical connections and separateness. Fournal of Personality and Social Psychology, 70, 349-361.

Bowker, A. (2004). Predicting friendship stability during early adolescence. fournal of Early Adolescence, 24, 85-112.

Bowlby, J. (1969). Attachment and loss:Vol. 1. Attachment. London: Hogarth Press. Brendgen, M., Vitaro, F., Doyle, A., Markiewicz, D., \& Bukowski, W. (2002). Same-sex peer relations and romantic relationships during early adolescence: Interactive links to emotional, behavioral, and academic adjustment. MerrillPalmer Quarterly, 48, 77-103.

Brown, B.B. (1999). "You're going out with who?": Peer group influence on adolescent romantic relationships. In W. Furman, B.B. Brown, \& C. Feiring (Eds.), The development of romantic relationships in adolescence (pp. 291-239). Cambridge: Cambridge University Press.

Cantril, H. (1965). The pattern of human concerns. New Jersey: Rutgers University Press.

Cohen, J. (1992). A power primer. Psychological Bulletin, 112, 155-159.

Collins, N., \& Read, S. (1990). Adult attachment, working models, and relationship quality in dating couples. Fournal of Personality and Social Psychology, 58, 644-663.

Collins, W., \& Laursen, B. (2000). Adolescent relationships: The art of Fugue. In C. Hendrick, \& S. Hendrick (Eds.), Sage sourcebook on close relationships (pp. 59-70). Thousand Oaks, CA: Sage.

Conger, R., Cui, M., Bryant, C., \& Elder, G. (2000). Competence in early adult romantic relationships: A developmental perspective on family influences. fournal of Personality and Social Psychology, 79, 224-237.

Connolly, J., Furman, W., \& Konarski, R. (2000). The role of peers in the emergence of heterosexual romantic relationships in adolescence. Child Development, 71, 1595-1408.

Connolly, J., \& Johnson, A. (1996). Adolescent's romantic relationships and the structure and quality of their close interpersonal ties. Personal Relationships, 3, 185-195.

Daley, S., \& Hammen, C. (2002). Depressive symptoms and close relationships during the transition to adulthood: Perspectives from dysphoric women, their best friends, and their romantic partners. Fournal of Consulting and Clinical Psychology, 70, 129-141.

Değirmencioğlu, S., Urberg, K., Tolson, J., \& Richard, P. (1998). Adolescent friendship networks: Continuity and change over the school year. MerrillPalmer Quaterly, 44, 313-337.

Diekstra, R., Garnefski, N., de Heus, P., de Zwart, R., van Praag, B., \& Warnaar, M. (1991). Scholierenonderzoek 1990; gedrag en gezondheid [Pupils'study 1990; behaviour and health]. Den Haag: Nibud. 
Duemmler, S., \& Kobak, R. (2001). The development of commitment and attachment in dating relationships: Attachment security as relationship construct. Fournal of Adolescence, 24, 401-415.

Duncan, T., Duncan, S., Strycker, L., Li, F., \& Alpert, A (1999). An introduction to latent growth curve modelling: Concepts, issues, and applications. Mahwah, NJ: Lawrence Erlbaum.

Erikson, E. (1968). Identity, youth and crisis. New York: Norton.

Feldman, S., Gower, L., \& Fischer, L. (1998). Family relationships and gender as predictors of romantic intimacy in young adults: A longitudinal study. Fournal of Research on Adolescence, 8, 263-286.

Furman, W. (1999). The role of peer relationships in adolescent romantic relationships. In W.A. Collins \& B. Laursen (Eds.), Minnesota Symposium on Child Development:Vol. 29. Relationships as developmental contexts (pp. 172-202). Hillsdale, NJ: Erlbaum.

Furman, W., Simon, V., Shaffer, L., \& Bouchey, H. (2002). Adolescents' working models and styles for relationships with parents, friends, and romantic partners. Child Development, 73, 241-255.

Furman, W., \& Wehner, E. (1994). Romantic views: Toward a theory of adolescent romantic relationships. In R. Montemayor, G. Adams, \& G. Gullotta (Eds.), Relationships during adolescence (pp. 168-195). Thousand Oaks, CA: Sage.

Goldberg, D.P. (1978). Manual of the general health questionnaire. Horsham: General Practice Research Unit.

Harter, S. (1985). Competence as a dimension of self-evaluation: Toward a comprehensive model of self-worth. In R. Leahy (Ed.), The development of the self (pp. 55-122). New York: Academic Press.

Hazan, C., \& Shaver, P. (1987). Romantic love conceptualized as an attachment process. Fournal of Personality and Social Psychology, 52, 511-524.

Helsen, M., Vollebergh, W., \& Meeus, W. (1999). Psychosociale problemen in de adolescentie: de samenhang met hechting aan ouders en vrienden en identiteit [Psychosocial problems in adolescence: Associations with parental and peer attachment and identity]. Nederlands Tijdschrift voor de Psychologie, 54, 256-275.

Helsen, M., Vollebergh, W., \& Meeus, W. (2000). Social support from parents and friends and emotional problems in adolescence. fournal of Youth and Adolescence, 29, 319-335.

Joyner, K., \& Udry, J. (2000). You don't bring me anything but down: Adolescent romance and depression. Fournal of Health and Social Behavior, 41, 369-391.

Katz, J., \& Beach, S. (1997). Self-verification and depressive symptoms in marriage and courtship: A multiple pathway model. fournal of Marriage and the Family, 59, 903-914.

Kienhorst, I., Wilde de, E., van den Bout, J., \& Diekstra, R. (1990). Psychometrische eigenschappen van een aantal zelfrapportage vragenlijsten over (on)welbevinden [Psychometric characteristics of self report questionnaires of psychological well being]. Nederlands Tijdschrift voor de Psychologie, 45, 122-133.

Kurdek, L. (1991). The relations between reported well-being and divorce history, availability of a proximate adult, and gender. Fournal of Marriage and the Family, 53, 71-78.

Kuttler, A., La Greca, A., \& Prinstein, M. (1999). Friendship qualities and social-emotional functioning of adolescents with close, cross-sex friendships. fournal of Research on Adolescence, 9, 339-366.

La Greca, A., \& Harrison, H. (2005). Adolescent peer relations, friendships, and romantic relationships: Do they predict social anxiety and depression? fournal of Clinical Child and Adolescent Psychology, 34, 49-61.

Lee, G., Seccombe, K., \& Shehan, C. (1991). Marital status and happiness: An analysis of trend data. Fournal of Marriage and the Family, 51, 839-844.

Marks, N., \& Lambert, J. (1998). Marital status continuity and change among young and midlife adults: Longitudinal effects on psychological well-being. fournal of Family Issues, 19, 652-686.

Meeus, W. (1994). Psychosocial problems and social support in adolescence. In
F. Nestman \& K. Hurrelmann (Eds.), Social networks and social support in childhood and adolescence (pp. 241-255). Berlin: De Gruyter.

Meeus, W. (1996). Studies on identity development in adolescence: An overview of research and some new data. Fournal of Youth and Adolescence, 25, 569-598.

Meeus, W., Branje, S., \& Overbeek, G. (2004). Parents and partners in crime: A six year longitudinal study on changes in supportive relationships and delinquency in adolescence and young adulthood. Fournal of Child Psychology and Psychiatry, 45, 1288-1298.

Meeus, W., \& 't Hart, H. (1993). Fongeren in Nederland [Young people in the Netherlands]. Amersfoort: Academische Uitgeverij.

Miller, J., \& Hoicowitz, T. (2004). Attachment contexts of adolescent friendship and romance. Fournal of Adolescence, 27, 191-2006.

Neeman, J., Hubbard, J., \& Masten, A. (1995). The changing importance of romantic relationship involvement to competence from late childhood to adolescence. Development and Psychopathology, 7, 727-750.

Neyer, F., \& Asendorf, J. (2001). Personality-relationship transaction in young adulthood. Fournal of Personality and Social Psychology, 81, 1190-1204.

Nieder, T., \& Seiffge-Krenke, I. (2001). Coping with stress in different phases of romantic development. Fournal of Adolescence, 24, 297-311.

Prentice, D., \& Miller, D. (1992). When small effects are impressive. Psychological Bulletin, 112, 160-164.

Rispens, J., Hermanns, J., \& Meeus, W. (Eds.) (1996). Opvoeden in Nederland [Parenting in the Netherlands]. Assen: Van Gorcum.

Rusbult, C.E. (1983). A longitudinal test of the investment model: The development (and deterioration) of satisfaction and commitment in heterosexual involvements. Fournal of Personality and Social Psychology, 45, 101-117.

Rusbult, C., Martz, J., \& Agnew, C. (1998). The investment model scale: Measuring commitment level, satisfaction level, quality of alternatives, and investment size. Personal Relationships, 5, 357-391.

Scharf, M., \& Mayseless, O. (2001). The capacity for romantic intimacy: Exploring the contribution of best friend and marital and parental relationship. fournal of Adolescence, 24, 379-399.

Segrin, C., Powell, H., Givertz, M., \& Brackin, A. (2003). Symptoms of depression, relational quality, and loneliness in dating relationships. Personal Relationships, 10, 25-36.

Seiffge-Krenke, I. (2000). Diversity in romantic relations of adolescents with varying health status: Links to intimacy in close friendships. Fournal of Adolescent Research, 15, 611-637.

Seiffge-Krenke, I. (2003). Testing theories of romantic development from adolescence to young adulthood: Evidence of a developmental sequence. International fournal of Behavioral Development, 27, 519-531.

Seiffge-Krenke, I. (2006). Coping with relationship stressors: The impact of different working models of attachment and links to adaptation. Fournal of Youth and Adolescence, 35, 25-39.

Seiffge-Krenke, I., Shulman, S., \& Klessinger, N. (2001). Adolescent precursors of romantic relationships in young adulthood. Fournal of Social and Personal Relationships, 18, 327-346.

Shulman, S., \& Scharf, M. (2000). Adolescent romantic behaviors and perceptions: Age- and gender-related differences, and links with family and peer relationships. Fournal of Research on Adolescence, 10, 99-118.

Simpson, J. (1990). Influence of attachment styles on romantic relationships. fournal of Personality and Social Psychology, 59, 971-980.

Sullivan, H.S. (1953). The interpersonal theory of psychiatry. New York: Norton.

'T Hart, H. (1992). Opzet en uitvoering van het WIL-panel 1 en 2 [Design and data collection of the Utrecht Study of Adolescent Development 1 and 2]. Unpublished manuscript, Department of Youth, Family and Life Course, Utrecht University.

Zimmer-Gembeck, M., Siebenbruner, J., \& Collins, W. (2001). Diverse aspects of dating: Associations with psychosocial functioning from early to middle adolescence. Fournal of Adolescence, 24, 313-336. 